\title{
On controllability for a class of second-order differential inclusions
}

\section{AURELIAN CERNEA}

\section{ABSTRACT.}

By using a suitable fixed point theorem a sufficient condition for controllability is obtained for a Sturm-Liouville type differential inclusion in the case when the right hand side has convex values.

\section{REFERENCES}

[1] Benchohra, M. and Ntouyas, S. K., Controllability for functional differential and integrodifferential inclusions in Banach spaces, J. Optim. Theory Appl. 113 (2002), 449-472

[2] Castaing, C. and Valadier, M., Convex Analysis and Measurable Multifunctions, Lectures Notes in Mathematics 580, Springer, Berlin, 1977

[3] Cernea, A. Continuous version of Filippov theorem for a Sturm-Liouville type differential inclusion, Electronic J. Diff. Eq. 2008 (2008), No. 53, 1-7

[4] Cernea, A. Sturm-Liouville type differential inclusions in non separable Banach spaces, Math. Reports, 10 (60) (2008), 205-211

[5] Cernea, A. A Filippov type existence theorem for a class of second-order differential inclusions, J. Inequal. Pure Appl. Math. 9 (2008), No.2, 1-6

[6] Chang, Y. K. and Li, W. T., Existence results for second order impulsive functional differential inclusions, J. Math. Anal. Appl. 301 (2005), 477-490

[7] Lasota A. and Opial Z., An application of the Kakutani-Ky-Fan theorem in the theory of ordinary differential equations, Bull. Acad. Polon. Sci. Math., Astronom. Physiques, 13 (1965), 781-786

[8] Liu, Y., Wu, J. and Li, Z., Impulsive boundary value problems for Sturm-Liouville type differential inclusions, J. Sys. Sci. Complexity 20 (2007), 370-380

[9] Martelli, M., A Rothe's type theorem for noncompact acyclic-valued map, Boll. Unione Matemat. Italiana 11 (1975), 70-76

FACULTY OF MATHEMATICS AND INFORMATICS

UNIVERSITY OF BUCHAREST

ACADEMIEI 14, 010014 BUCHAREST, ROMANIA

E-mail address: acernea@ fmi . unibuc.ro 